\title{
Factors Shaping Uptake of Antenatal Care in Surabaya Municipality, Indonesia: A Qualitative Study
}

\author{
Lisa Jones ${ }^{1 *}$, Nyoman Anita Damayanti ${ }^{2}$, Nicola Wiseman ${ }^{1,2}$, Neil Harris ${ }^{1,2}$
}

${ }^{1}$ School of Medicine and Dentistry, Griffith University, Queensland, Australia, ${ }^{2}$ Department of Health and Administration Policy, Faculty of Public Health, Universitas Airlangga, Surabaya, Indonesia

\begin{abstract}
Five focus group discussions (FGDs) with 61 pregnant women were conducted in June and July 2019 at primary health care (PHC) services within five urban areas of Surabaya, Indonesia. In addition, five semi-structured interviews with five midwives were carried out to explore the experiences of pregnant women accessing Antenatal Care (ANC) and the factors shaping uptake of ANC services. Data were audio-recorded, transcribed, and translated into English, and analyzed using thematic analysis. Findings from focus group discussions suggested that fears of negative diagnosis before initial ANC appointment and personal beliefs and myths surrounding pregnancy may delay uptake of ANC. Further, the influence of husbands, family, and friends and long waiting times with overcrowding leading to limited seating shaped timely access and return visits. In addition, feeling comfortable with the quality of the service and receiving a friendly service from the practitioners assisted women in feeling comfortable to return. Finally, midwives acknowledged feeling afraid of being referred to a hospital if deemed a high-risk pregnancy-shaped return ANC visits. The findings highlighted several factors needing to be addressed to increase the promptness of first ANC visits and ensure return visits to achieve great ANC coverage.
\end{abstract}

Keywords: antenatal care, maternal mortality, qualitative methods, thematic analysis

\section{Introduction}

Antenatal Care (ANC) is central to adequate healthcare to reduce maternal morbidity and mortality while improving infant survival and health. The leading causes of maternal mortality and morbidity in women aged 15 to 49 years in low and middle-income countries are complications during pregnancy and childbirth. ${ }^{1}$ Whilst hemorrhage (after birth), infections, pre-eclampsia and eclampsia during pregnancy, complications from delivery, and unsafe abortion as the major causes of nearly $75 \%$ of all maternal deaths. ${ }^{2}$ Namely, ANC provides essential education to women on recognizing signs of complication, consequently reducing mortality and promoting birth preparedness with a skilled birth attendant and/or facility. ${ }^{3,4}$ Further, ANC can provide effective interventions for preventing and treating other conditions such as anemia, pre-clampsia, and eclampsia. ${ }^{3}$ Since the consensus suggests that most maternal mortalities and morbidities are preventable, utilizing ANC as a preventative tool is essential, particularly for avoiding complications in childbirth.

Correspondence*: Lis Jones, School of Medicine and Dentistry, Griffith University, 1 Parklands Dr, Southport, 4215 Queensland, Australia, E-mail: lisa.jones@griffith.edu.au,Phone: +6175552 7820
Within Indonesia in 2017, it was estimated that ANC coverage for women aged $15-49$ years was $77 \%$ (women attending at least four ANC visits ${ }^{5}$ This coverage rate has decreased since 2012, with data showing a slow decline from $88 \%$ coverage. $^{5}$ Although the national ANC coverage (minimum four visits) may be considered acceptable at the current rate of $77 \%$, the maternal mortality ratio (MMR) of 126 per 100,000 live births in Indonesia remains unacceptably high compared to high- income country counterparts. 5,6

Although this demonstrates a decrease from the year 2000 (265 per 100,000 live births), this decline occurs at a much slower rate when compared to the Southeast Asian region, despite remarkable improvements in essential health and economic indicators. ${ }^{6,7}$ Whilst maternal mortality trends are steadily declining, uncertainty remains regarding the high ANC coverage rates not translating to lower MMRs. ${ }^{8}$

A study suggested that several factors may shape the uptake of ANC services across Indonesia. These factors can be conceptualized as individual circumstances, cul-

Received : March 02, 202

Accepted : April 28, 2021

Published: August 24, 2021 
tural and social dynamics, and community and health care conditions. ${ }^{9-17}$ Within Indonesia, this literature indicates that personal events influencing ANC uptake may include socioeconomic status, income, age, education, and whether a woman is pregnant with her first child.912 These factors interact with broader cultural and social factors within which a woman lives to shape ANC uptake. ${ }^{9,13-15}$ Further, community and health care conditions are believed to shape accessibility and uptake of ANC services, with women in urban areas much more likely to achieve adequate ANC visits. ${ }^{10,16}$ Shortage of qualified health providers and overcrowded facilities has also been suggested to influence ANC uptake. ${ }^{7,11,17}$

This study would explore the experiences of pregnant women accessing ANC within the urban areas of Surabaya. While current research indicated several influencing factors, there was limited qualitative literature exploring pregnant women's views in Surabaya City or elsewhere in Indonesia on utilizing ANC services. In addition, although national and local quantitative data could link specific determinants with ANC health-seeking behaviors, it did not explain or provide insight on potential community-based strategies for reducing maternal mortality. The findings would guide future research and support the planning of public health interventions improving both ANC services and uptake within this area. Public health promotion strategies and interventions must focus on ANC due to the evident link with reducing maternal mortality.

\section{Method}

Five focus group discussions (FGDs) with 61 pregnant women alongside five semi-structured individual interviews (SSIs) with five midwives within the city and urban areas of Surabaya were conducted to explore factors shaping uptake ANC services in Surabaya. Demographics were collected on FGD participants using selfreporting methods. Demographics of the midwives were not collected due to the low number of midwives interviewed and to keep confidentiality and anonymity when sharing the findings. The study was conducted at five separate primary health care (PHC) services located in North, North-East, South, West, and South-West Surabaya to include various facilities serving different demographic populations. A Puskesmas, hereby referred to as PHC, are a central plank of the Indonesian public health care system, with 63 situated within Surabaya. The PHC is considered to provide front-line health care for pregnant women accessing ANC services. Most PHC services offer comprehensive ANC, including access to pathology collection, dentistry services, onsite nutritionists and dieticians, ultrasound (sonography) equipment, and an onsite pharmacy with access to prenatal supplementation. All PHC that offered ANC services could be included within the study setting, with the final five facilities being chosen due to the connections between Universitas Airlangga and the Chiefs of the PHC services.

Five FGDs were conducted because it was in line with the scope of the research and with literature suggesting that four FGDs were sufficient to achieve code saturation. ${ }^{18}$ To be eligible to be involved within the FGDs, participants had to be pregnant or post-partum (gave birth within the last six months), an Indonesian Citizen who resided in Surabaya, 18 years or older, and had attended a PHC service for ANC. Participants who were post-partum or had already had multiple pregnancies were asked to report on their most recent pregnancy. In addition to the FGDs, five SSIs were carried out with midwives who had a direct role in the care of pregnant women at the five PHC services to offer additional perspective on the factors shaping uptake of ANC services.

FGD participants were purposively recruited from the targeted community. This ensured that the individuals associated with the phenomena were selected to be part of the study while accounting for limited resources. ${ }^{19}$ Through the connections between Universitas Airlangga and the PHC services around Surabaya, 61 pregnant women were recruited into the FGDs. These pregnant women either had attended the PHC services in the past or were there for the first appointment on the same day as FGD. Participants were recruited through the assistance of the midwife coordinator of the PHC services during their routine appointments. Alternatively, those attending the facility for their first appointment were recruited through the midwife coordinator by asking community health volunteers and the pregnant women in the community to know anyone or would like to be a part of the study. Further, one midwife working at each facility was approached by the FGD facilitators and asked if they would like to participate in the research and be involved in an SSI on the day of the FGD.

FGDs and SSIs were carried out in June and July of 2019 by a native Bahasa Indonesia speaker author in the national language of Bahasa Indonesia to ensure the inclusion of all participants. As the study was a collaboration between Australian and Indonesian authors, English translations were also provided at FGDs and SSIs to the non-Bahasa Indonesia speaking author to follow the discussion and direct where appropriate. The topic guides for the FGDs and SSIs were developed in English and translated to Bahasa Indonesia after a literature review and discussion with academic authors within the maternal and child health field at Universitas Airlangga, Surabaya. These translations were checked by a minimum of two native Bahasa Indonesia-speaking authors who were also fluent in English. An overview of the FGD and SSI guide is provided in Table 1 and Table 2, respec- 
tively. The method of FGDs with pregnant women was well suited to this study as it encouraged participants to explore and share their personal views to build a shared understanding of the factors shaping their access to ANC services. ${ }^{20}$ This method was particularly appropriate given the sensitivity of cultural and family factors shaping access. Utilizing SSIs with midwives respected their expert status in delivering ANC services and enabled the collection of a different operational perspective on access to ANC services. ${ }^{21}$ This approach facilitated a more comprehensive understanding of the uptake of ANC by encouraging the convergence of information from various sources. All FGDs and SSIs were recorded, transcribed, and translated into English for analysis. A minimum of two native Bahasa Indonesia-speaking authors carried out and checked translations to ensure accuracy. Further, once the results were analyzed, a copy was sent to the translators and the second author fluent in both languages to ensure no meaning was misinterpreted by the non-Bahasa speaking primary author.

Thematic analysis was utilized to identify and describe both implicit and explicit ideas from the data collected. This approach includes coding and classifying data into concepts, categories, or themes and consequently interpreting the resulting thematic structures by seeking commonalities, relationships, and patterns within the data. ${ }^{22}$ Data from the transcripts were linked to these overarching ideas, then further organized into themes and sub- themes to help interpret and evidence the results.

Ethics approval was obtained from Griffith University (GU) Human Research Ethics Committee (GU ref no: 2019/424) and Universitas Airlangga (ref no: 15494KEPK). All participants gave informed written consent. All FGDs and SSIs were audio-recorded and later translated and transcribed to English after approval was obtained from all participants. In addition to informed consent, ethical considerations were followed to ensure participants were informed about their rights to withdraw from the study at any time, confidentiality, and assured no harm would come to their reputation at the PHC service or their career. No financial incentive was provided to the participants. However, individuals in the FGDs were provided a free lunch while SSI participants were provided with lunch and a small token of appreciation.

\section{Results}

Sixty-six participants were involved in this study, including sixty-one FGD participants and five semi- structured interview participants. Demographic details of FGD participants are summarized in Table 3. The FGDs and SSIs identified several, often interrelated factors shaping the uptake of ANC. These findings were aligned with several broad categories, including individual circumstances, cultural and social dynamics, and community and health care conditions. Table 4 presents a taxonomy of the categories, themes, sub-themes, and associ-

Table 1. An Overview of the Focus Group Discussion Guide

\begin{tabular}{ll}
\hline Theme & Guiding Questions \\
\hline Perceptions & What does Antenatal Care (ANC) mean to you? \\
Comfort of facility & When you first arrived at the facility, how did you feel? \\
& Did you feel comfortable attending this PHC service? Why/Why not? \\
Potential barriers to ANC & What is your experience accessing ANC - did you experience any \\
& barriers to arriving here today, e.g., transport, money, weather? \\
Cultural factors in attending ANC & $\begin{array}{l}\text { Did you alone decide to utilize ANC for your pregnancy or most recent } \\
\text { pregnancy? }\end{array}$ \\
Promoting ANC & Would you promote ANC to your friends and family? Could you see \\
& your friends and family using these services? \\
\hline
\end{tabular}

Table 2. An Overview of the Semi-Structured Interview Guide

\begin{tabular}{|c|c|}
\hline Theme & Selected Questions \\
\hline Comfort of facility & $\begin{array}{l}\text { How important do you think it is for the pregnant women accessing this this PHC ser- } \\
\text { vice to feel safe with the quality of the services? Why/Why not? }\end{array}$ \\
\hline Accessibility of Antenatal Care (ANC) & $\begin{array}{l}\text { Do you often have space and availability every day to book an appointment and see a } \\
\text { pregnant woman? } \\
\text { How long does it usually take from booking an ANC appointment to seeing a } \\
\text { health professional staff? }\end{array}$ \\
\hline Potential barriers to ANC & $\begin{array}{l}\text { Are there any barriers you can think of that would stop someone from accessing ANC? } \\
\text { Transport, weather, money, disapproving family members, traditional birth atten- } \\
\text { dants instead, or other cultural factors? }\end{array}$ \\
\hline Cultural factors in attending ANC & $\begin{array}{l}\text { Who, other than the pregnant women, usually attends the ANC sessions? } \\
\text { Family members, friends? } \\
\text { Do you think this is important for pregnant women? }\end{array}$ \\
\hline
\end{tabular}


Table 3. Demographics of Study Sample in Focus Group Discussion $(n=61)$

\begin{tabular}{|c|c|c|c|}
\hline Variable & Category & $\mathbf{n}$ & $\%$ \\
\hline \multirow[t]{5}{*}{ Age (years) } & $18-24$ & 4 & 6.6 \\
\hline & $25-29$ & 6 & 9.8 \\
\hline & $30-34$ & 4 & 6.6 \\
\hline & $35+$ & 7 & 11.5 \\
\hline & Unknown & 40 & 65.5 \\
\hline \multirow{8}{*}{$\begin{array}{l}\text { Pregnancy number at time of } \\
\text { focus group discussion (FGD) }\end{array}$} & 1 (first pregnancy) & 8 & 13.1 \\
\hline & 2 & 16 & 26.3 \\
\hline & 3 & 6 & 9.8 \\
\hline & 4 & 7 & 11.5 \\
\hline & $5+$ & 2 & 3.3 \\
\hline & Has been pregnant before (pregnancy & & \\
\hline & number not disclosed) & 11 & 18.0 \\
\hline & Unknown & 11 & 18.0 \\
\hline \multirow[t]{2}{*}{ Marital/relationship status } & Married & 49 & 80.3 \\
\hline & Unknown & 12 & 19.7 \\
\hline \multirow[t]{6}{*}{ Highest level of education } & Elementary & 10 & 16.4 \\
\hline & Junior high school & 11 & 18.0 \\
\hline & Senior high school & 26 & 42.6 \\
\hline & Diploma & 2 & 3.3 \\
\hline & Bachelor & 1 & 1.7 \\
\hline & Unknown & 11 & 18.0 \\
\hline \multirow[t]{6}{*}{ Employment Status } & Not working & 37 & 60.6 \\
\hline & Employed part time & 2 & 3.3 \\
\hline & Employed full time & 3 & 4.9 \\
\hline & Self-employed & 1 & 1.7 \\
\hline & Other (Homemaker) & 2 & 3.3 \\
\hline & Unknown & 16 & 26.2 \\
\hline \multirow[t]{7}{*}{ Monthly household income (IDR) } & $<500,000(<35$ USD $)$ & 1 & 1.7 \\
\hline & 500,000-1,000,000 (35-70 USD) & 4 & 6.6 \\
\hline & 1,000,001-2,000,000 (71-138 USD) & 12 & 19.7 \\
\hline & $2,000,001-3,000,000$ (139-207 USD) & 9 & 14.7 \\
\hline & $3,000,001-4,000,000$ (208-278 USD) & 9 & 14.7 \\
\hline & $4,000,001-6,000,000$ (279-414 USD) & 4 & 6.6 \\
\hline & Unknown & 22 & 36.0 \\
\hline
\end{tabular}

ated quotes shaping the uptake of ANC derived from the thematic analysis of the data.

\section{Individual Circumstances}

Several midwives commented that women often had limited knowledge of pregnancy risks or emergency signs. One midwife explained:

"They (pregnant women) think that pregnancy is the normal process. So, they have in their mind that it is okay if they do not go to PHC".

Further, a delay in the uptake of ANC was shaped by not experiencing nausea or feeling that they were too old to be pregnant.

"First time I came to midwife when my pregnancy had been three months. I did not realize that I was pregnant already because there is no symptom like dizziness or nausea."

Despite the shared understanding of ANC's importance, with a consensus of wanting to "know my baby is healthy and developing," a standard view reported by the pregnant women was a fear of receiving a negative diagnosis upon their first visit to the PHC service. For example, one mother explained:
"...There was a mother who felt scared to check from the first time she knew she was pregnant to 9 months of pregnancy; she never went to the PHC service... her condition became critical in labor. Fortunately, both mother and baby were okay."

The majority of women within the current study population held Badan Penyelenggara Jaminan Sosial Kesehatan (BPJS), which administers the Indonesian national health insurance making ANC services accessible. Similarly, for those who do not have BPJS, it was shared that the services were perceived as inexpensive, so there was no financial problem in accessing ANC.

"I choose this PHC service because the PHC service is cheap."

\section{Cultural and Social Dynamics}

The results of this study showed that nearly all the participants had a personal belief about pregnancy or shared the views of others when considering when they could come to PHC and when they could safely leave the house. It emerged from this study that there was often a delayed initiation of ANC due to upholding beliefs.

"I came to PHC service for the first time in the fifth 
Table 4a. Summary of Categories, Themes, Sub-Themes, and Associated Quotes Shaping Uptake of Antenatal Care

\begin{tabular}{lll}
\hline Category & Theme & Sub-theme \\
\hline Individual circumstances & Perceptions & $\begin{array}{l}\text { Perceived knowledge of } \\
\text { pregnancy }\end{array}$
\end{tabular}

Associated Quote

"They (pregnant women) think that pregnancy is the normal process. So, they have in their mind that it is okay if they do not go to PHC." (MW5-P3)

"I didn't realize. One day my body was not feeling well; only in the third month, I started to feel nauseous. I did a check-up at the hospital, and it turns out I am 3 months pregnant. "Imitates talking to the doctor" "Really, doctor? I'm already old, I am 40 years old". (FGD2-P1)

"First time I came to midwife when my pregnancy had been three months. I did not realize that I was pregnant already because there is no symptom like dizziness or nausea." (FGD5-P1)

Cultural and social dynamics
Myths associated with pregnancy
Influence of family Decision making and friends
Perceived importance of Antenatal Care (ANC)

Fears associated with attending Primary Health Care $(\mathrm{PHC})$

Affordability of ANC

"It is important to go to the PHC service because I want to know not only my pregnancy but the nutrition needs and dietary habits whilst I am pregnant." (FGD1-P3)

"To know my baby is healthy and developing." (FGD5-P2)

"...There was a mother who felt scared to check from the first time she knew she was pregnant to 9 months of pregnancy; she never went to the PHC service ... her condition became critical in labor. Fortunately, both mother and baby were okay." (FGD3-P2)

"I had a fear for the first time I came to the PHC service... I was afraid to be diagnosed with a problem in my pregnancy. I was afraid to find out." (FGD1-P4)

"I am afraid at the PHC service if it does not give me an excellent service. But the service is okay, but I am more concerned if there is something wrong with my baby." (FGD1-P4)

"I choose this PHC service because the PHC service is cheap." (FGD1-P5)

"There is no problem with accessibility or transportation or cost because if they have a national identity or health insurance, it is all free." (MW1-P3)

"After I came to the PHC service, my beliefs do not change my mind about going outside after $5 \mathrm{pm}$, except if there is an emergency like if the baby is sick, or if I am sick... I do not know the reason why I can't go outside. It is just from my family." (FGD1-P5)

"I came to PHC service for the first time in the fifth month ... The reason I only came in the fifth month is that I had nausea before, and I was told (by my family) that nausea should end first before I can go to the PHC service." (FGD1-P6)

"I cannot eat after $9 \mathrm{pm}$. Sometimes I feel hungry at midnight, but I am not allowed to eat... It is not good, for my health, my parents said." (FGD1-P1-2) "It is pivotal (for pregnant women to feel safe). Most of the people in this area are middle-to-low-income and have a low level of education. So, they have to be taken care of. If not, they will easily believe in myths..." (MW3-P2)

"My husband recommends this PHC service for me. I have heard from my family and friends to come here." (FGD1-P1)

"... it is my body, my authority, not my husbands. I don't need permission from my husband." (FGD3-P3)

Attendance within ANC "Most of them are accompanied by a friend, their mother, or their husband." (MW4-P3)

"It is pivotal (for both pregnant woman and father of the baby to attend the visits) for the information to be known by the pregnant woman but also by her husband. Perhaps, the husband has something they want to share with the midwife. So, there is good communication between everyone." (MW3-P2)

Shame from the community "When she (neighbor) went to give birth, she had only checked her pregnancy once. One month before giving birth. Sometimes it is a shame when the pregnancy is too close to the first child." (FGD2-P4) month... The reason I only came in the fifth month is that I had nausea before, and I was told (by my family) that nausea should end first before I can go to the PHC service."

Midwives within this study commented on the importance of health promotion and education to debunk such myths within the community.

"It is pivotal (for pregnant women to feel safe). But, unfortunately, most people in this area are middle-to-low- income and have a low level of education... So, they have to be taken care of. If not, they will easily believe in myths..." (MW3-P2)

Within this study, several women commented that their husbands, friends, or family members had recommended primary health care through PHC services. Due to the significant influence from partners or family members on recommendations regarding health care, midwives of this study suggested involving husbands within 
Kesmas: Jurnal Kesehatan Masyarakat Nasional (National Public Health Journal). 2021; 16 (3): 189-198

Table 4b. Summary of Categories, Themes, Sub-Themes, and Associated Quotes Shaping Uptake of Antenatal Care

\begin{tabular}{|c|c|c|c|}
\hline Category & Theme & Sub-theme & Associated Quote \\
\hline \multirow[t]{8}{*}{$\begin{array}{l}\text { Community and health } \\
\text { care conditions }\end{array}$} & \multirow[t]{4}{*}{ Availability of services } & Waiting area & $\begin{array}{l}\text { "They need to add more seats, as sometimes I have to stand up. There are a lot } \\
\text { of pregnant women that wait by standing." (FGD1-P5) } \\
\text { "We have facilitated the patient who comes here with some entertainment such } \\
\text { as reading stations and a playground for children... We hope they will not feel } \\
\text { bored while waiting." (MW5-P4) }\end{array}$ \\
\hline & & Timely services & $\begin{array}{l}\text { "I went to a midwife clinic for my first pregnancy because I did not need to } \\
\text { wait." (FGD4-P1) } \\
\text { "I think they should add more professionals because there are many patients, } \\
\text { so we need more time with the professional to consult more." (FGD1-P5) } \\
\text { "They (pregnant women) feel the queue is the biggest barrier... the wait" } \\
\text { (MW1-P3) }\end{array}$ \\
\hline & & Online bookings & $\begin{array}{l}\text { "Nowadays, we can register it online. The registration is fast, but the queue is } \\
\text { long. The service sometimes does not match to the time written as it is some } \\
\text { times delayed." (FGD4-P5) }\end{array}$ \\
\hline & & Variety of services offered & $\begin{array}{l}\text { "In the first visit, a pregnant woman will get a general health check and labo- } \\
\text { ratory examination or complete blood examination, regarding HIV, Hepatitis B, } \\
\text { and others...If there are problems or risks, the pregnant woman will be reffer- } \\
\text { ed." (MW3-P1) }\end{array}$ \\
\hline & \multirow[t]{2}{*}{ Getting to the facility } & Transport & $\begin{array}{l}\text { "No, there is no problem because the transportation is easy." (FGD1-P4) } \\
\text { "For transportation, actually there is no barrier, but for one village far from } \\
\text { here, the village provides transport for the patient to the PHC service. Cadre } \\
\text { accompanies them. It is } 10 \mathrm{~km} \text {, because of the traffic jam, so it takes } 30 \text { min- } \\
\text { utes at least." (MW4-P3) }\end{array}$ \\
\hline & & The closeness of the facility & $\begin{array}{l}\text { "I choose here (PHC) because it's nearby." (FGD4-P2) } \\
\text { "In the future, I would come here, but not for pregnancy (plans to not have } \\
\text { anymore children) but for other services. It is because this PHC service is the } \\
\text { nearest place to come, and it is complete with services." (FGD1-P5) }\end{array}$ \\
\hline & $\begin{array}{l}\text { Patient-practitioner } \\
\text { rapport }\end{array}$ & & $\begin{array}{l}\text { "The service is excellent and efficient- the same as in the hospital. The quality } \\
\text { of health service is good, and the midwives here are good as we know them } \\
\text { from our previous pregnancies." (FGD1-P5) } \\
\text { "Sometimes there are doctors who care. Sometimes there are people who are } \\
\text { too annoyed by their patients." (FGD2-P6) } \\
\text { "The doctor is pleasant, he asks, "What do you feel? What's the complaint?" } \\
\text { It is nice for someone to care like that..." (FGD2-P6) } \\
\text { "There is a rumor at this public PHC service that the staffs are not good, which } \\
\text { is why some women choose not to come here. I have sacrificed a lot to improve } \\
\text { the coverage of pregnant women to come here." (MW5-P6) }\end{array}$ \\
\hline & $\begin{array}{l}\text { Midwife perceptions } \\
\text { on 'no-shows' }\end{array}$ & & $\begin{array}{l}\text { "The reason (pregnant women drop off for appointments) are they are afraid } \\
\text { when they are referred to the hospital, or they go back to their hometown or } \\
\text { their family who can help them to take care of their baby." (MW5-P5) } \\
\text { "Commonly, they (pregnant women) come back to here because they know the } \\
\text { process, and they're familiar with the staff so they feel comfortable to come } \\
\text { back." (MW1-P3) } \\
\text { "We, as a midwife, arrange the schedule for the upcoming antenatal visit rou- } \\
\text { tinely. So, they have already known when they have to come back. In addition, } \\
\text { I also have cadre as my extension to follow up the condition of pregnant } \\
\text { woman and remind them to come to the PHC service." (MW2-P1) }\end{array}$ \\
\hline
\end{tabular}

the ANC visits as pivotal:

"It is pivotal (for both pregnant woman and father of the baby to attend the visits) for the information to be known by the pregnant woman but also by her husband. Then, perhaps, the husband has something they want to share with the midwife. So, there is good communication between everyone." (MW3-P2)

Despite the potential influence of family and friends in decision making, many women from this study population shared that ultimately the decision was their own:

"... it is my body, my authority, not my husbands. I don't need permission from my husband".

This study discussed the shame felt by the pregnant women from the community if the pregnancy was too close to a previously born child. Indeed, the participants shared that not seeking ANC or slow uptake of ANC was often shaped by this shame experienced,

"So when she (neighbor) went to give birth, she had only checked her pregnancy once. One month before giving birth. Sometimes it is a shame when the pregnancy is too close to the first child."

\section{Community and Health Care Conditions}

The participants in this study expressed their concern over the limited waiting seats within PHC services. This often resulted in the pregnant women having to "wait by 
standing", and several suggested additional seats would facilitate a more comfortable waiting area. While women reported choosing other, sometimes less equipped facilities due to the waiting time:

"I went to a midwife clinic (private) for my first pregnancy because I did not need to wait."

If women choose not to go to a PHC service, other ANC options include private hospitals, traditional birth attendants, or private midwife clinics. Although often conventional birth attendants or private midwives have access to all the necessary facilities or the skills required to provide comprehensive ANC. However, despite the want for more seats in the waiting area, the midwives shared that the staff tried their best to provide an engaging waiting area through.

"...entertainment such as reading stations and a playground (inside) for children... We hope they will not feel bored while waiting."

Despite the long waiting times, the participants of this study commented on the effectiveness of the online booking system and the ability to book through WhatsApp streaming processes.

"Nowadays, we can register it online. The registration

is fast, but the queue is long. The service sometimes

does not match to the time written as it is sometimes

delayed."

Further, participants commented that their consults would often be short due to the high number of patients at the PHC services. Participants felt that they were unable to receive all the information they required.

"I think they should add more professionals because

there are many patients, so we need more time with the professional to consult more."

In this study, participants shared that there was no problem getting to the facility due to living close to the facility and/or having access to transport. In addition, several women shared that the facilities could easily be accessed by walking or riding their scooters in less than 10 minutes, and many would come to the facility for reasons other than their pregnancy.

"In the future, I would come here, but not for pregnancy (plans to not have any more children) but for other services. This is because this PHC is the nearest place to come, and it is complete with services."

One midwife shared that cadre, or community health volunteers, also have a vital role as maternal health promoters, often accompanying pregnant women from their community to the PHC service.

"For transportation, actually there is no barrier, but for one village far from here, the village provides transport for the patient to the PHC service. Cadre accompanies them. It is $10 \mathrm{~km}$, because of the traffic jam, so it takes 30 minutes at least."

The patients highlighted the importance of satisfac- tion between the patient and the health care providers within this study. Namely, the quality (perception of) and friendliness of service delivered, alongside feeling like enough information was shared, "The doctor is pleasant, he asks, "What do you feel? What's the complaint?" It is nice for someone to care like that." In contrast, rumors associated with one PHC staff being inadequate influenced the pregnant women in the area accessing that facility. One of the midwives explained that women in the area chose not to come to the facility, as they believed the staff were "not good". Further, this midwife shared that "I have sacrificed a lot to improve the coverage of pregnant women to come here", such as spending time outside of work hours to build rapport and trust with the pregnant women in the community. Conversely, one midwife explained that several patients come to their PHC service due to the connections and relationships made with their patients.

In some cases, the midwives shared that it was because the pregnant women were afraid that if they attend an ANC appointment and there are concerns with their pregnancy, they will be referred to the hospital. For many women, this raises feelings of apprehension. It was believed that being referred to a hospital with a high-risk pregnancy means they would need to undergo a cesarean section at childbirth. Conversely, some women also no longer returned for follow-up appointments as they moved away or back to their hometowns.

"The reason (pregnant women drop off for appointments) is they are afraid when they are referred to the hospital, or they go back to their hometown or their family who can help them to take care of their baby." In contrast, midwives suggested that the comfortable feeling facilitated return visits and to avoid no-shows. It was essential to deliver a friendly and caring service.

"Commonly, they (pregnant women) come back here because they know the process and familiar with the staff, so they feel comfortable to come back."

While midwives shared the importance of the kaderkader/cadre (community health volunteers) as a critical service within communities facilitating outreach and promoting utilization of ANC to stop 'no-shows'.

"We, as a midwife, arrange the schedule for the upcoming antenatal visit routinely. So, they have already known when they have to come back. In addition, I also have cadre as my extension to follow up the condition of the pregnant women and remind them to come to the PHC service."

\section{Discussion}

The findings suggested that limited awareness of being pregnant, alongside personal beliefs and myths in some women, shaped the rapid uptake of ANC. In a separate study, it was demonstrated that some women as- 
sociate symptoms of nausea as the first signs of pregnancy. However, the authors acknowledge that this symptom typically occurs during pregnancy weeks $6-8$ and peaks in weeks 11-13.23 Consequently, not having nausea until the first trimester could shape the early uptake of ANC. ${ }^{23}$ Promotion and investment in female education in Surabaya district should be considered to improve the early recognition of pregnancy and early uptake of ANC. At the same time, personal beliefs and myths had a significant role in this study population in delaying ANC uptake. Although midwives shared that they would consult their patients one-on-one and work with kader-kader to help counteract any myths within the community, these myths still influenced ANC uptake. Likewise, within a South African study, one of the well-documented risk factors for late uptake of ANC was cultural beliefs. ${ }^{24}$ Therefore, efforts to debunk myths at the community level are essential due to the im- portance of these myths by communities.

It must be noted that finances or accessibility were not considered a constraint within this study. Although it is well recognized in the literature within low-middle income countries, the challenge that financial constraints and proximity of services impose on ANC uptake. ${ }^{25,26}$ Therefore, for this study population, there was a consensus that ANC was both affordable and accessible, this needs to be continued to be considered in future health promotion interventions as the finding cannot be generalized for the whole of Surabaya and Indonesia. Certainly, the strong beliefs and attitudes towards pregnancy held by husbands, families, and friends could influence pregnant women's ideas on pregnancy and ANC uptake.

In a Balinese study on pregnant women, the findings showed that pregnant women tend to take advice from their family without questioning because of trust. ${ }^{27}$ Further, several admitted that they followed their family's advice to pleased them. ${ }^{27} \mathrm{~A}$ qualitative study in the United Kingdom investigating delayed access to ANC reported that women postponed uptake to avoid adverse family reactions on how they might cope with the birth of another child. ${ }^{28}$ Next, it was shown in Ethiopia that women who reported at least one ANC visit with their husbands were 6.27 times more likely to use skilled birth attendants than their counterparts who attended ANC alone. ${ }^{29}$ Consequently, it is vital to encourage partners, families, and friends in ANC and any current and future maternal and infant health promotion and educational campaigns to support positive outcomes in pregnancy.

A pressing finding of this study suggested that feeling comfortable with the facilities may be essential in shaping ANC uptake and return visits. Separate research explained that the long waiting times made the facilities less convenient and limited the enjoyment of the ser- vice. ${ }^{30}$ In some cases, it could act as a barrier to service uptake, with participants of this study choosing to leave the clinic or seek a private midwife rather than cueing at the PHC. ${ }^{30}$ Although the PHC services within this study utilized technology for booking appointments, the technology failed to inform women about the waiting time. A mixed-methods evaluation of e-booking in medical practices showed that patients appreciate using technology for appointments due to the flexibility and time sav- ings. ${ }^{31}$ While, a review on mHealth applications to improve antenatal and postnatal care in low and middle-income countries suggested that utilizing mHealth for education and behavior change communication such as short message service (SMS) or voice message reminder may enhance the uptake of health services. ${ }^{32}$ Current technology in Surabaya for booking appointments could include a function to inform patients on waiting times and if a delay in their appoint- ment will reduce long waiting times and improve the overall comfort of attending ANC appointments.

Finally, receiving quality care (perception of) and friendly, trustworthy service from the practitioners at the PHC services was a theme across all FGDs. In particular, one of the pregnant women receiving ANC from her local hospital exclaimed that she changed health care providers and health facilities due to the perceived adverse treatment from her doctor where she felt she was more of an annoyance, "Sometimes there are doctors who care, sometimes there are people who are too annoyed by their patients." While none of the other participants highlighted any negative patient-provider relationship interactions as a reason influencing their uptake of ANC, many believed it was a reason shaping the uptake of ANC within their communities. A qualitative study conducted in Malawi on the patient-provider relationship and ANC uptake showed that the patient-provider relationship appears to have a significant impact on ANC participation. ${ }^{33}$ Further, the study results suggested the attitudes of the health care provider can influence uptake of ANC and improve the patient-provider relationship, may increase ANC attendance, and consequently decrease pregnancy complications. ${ }^{33}$ In addition, a study exploring the provision and uptake of routine ANC services in low and middle-income countries reported that perceived poor quality of ANC could influence the uptake of services. ${ }^{34}$ Certainly, improving the (perception of) quality of the ANC delivered within the communities could improve ANC uptake and patient satisfaction.

Despite the study following a strict protocol, it is essential to recognize the limitations. First, all pregnant women were welcome to participate within the FGDs, whether it was their first pregnancy or returning after already having multiple pregnancies. It could have influenced results as a first-time mother could have different 
thoughts on ANC compared to mothers who have already experienced multiple pregnancies. Moreover, before the commencement of one FGD, the head of the PHC services was present, organizing the room and greeting the participants. Even though the head left before FGD, the presence at the beginning of FGD might have impacted the results. However, it was made clear within the informed consent that all thoughts shared were confidential and would not affect the participants' relationship with the health facility. In addition, in one FGD, a husband was present due to cultural factors. It could have altered the results of the study again. However, to have this participant involved within the FGD, it was vital to respect the wishes and allow the husband to sit in.

Due to the scope of the study, only five FGDs and SSIs were conducted. Therefore, the study's findings were limited to a small sample in the city and urban areas of Surabaya and those attending ANC services in PHC services. Consequently, the results should not be considered generalizable to the broader population. In contrast, it was also essential to consider that under-reporting was a distinct possibility within this setting due to potential recall bias or the sensitive nature of the questions. Finally, due to the FGDs and SSIs being a joint research project between Australian and Indonesian authors, translations from Bahasa Indonesia to English of the data were required. At times, meanings could be lost in translation; therefore, interpretation of the results in English could miss the true sense. In order to overcome this limitation, translations were checked by a minimum of two individuals, and the qualitative data was reviewed by the translators and the second author fluent in both languages to minimize meanings being lost in translation.

\section{Conclusion}

Despite a considerably high ANC coverage of $77 \%$ within Indonesia, this study highlighted several factors influencing the timely uptake of ANC. These factors primarily involve individual fears on a negative diagnosis and myths that delay ANC uptake rather than stopping attendance completely. Further, women experience shame from the community if their pregnancy is too close to previous pregnancies, again delaying ANC uptake. Additionally, overcrowded PHC services resulting in long wait time may shape return ANC visits. Finally, a factor that may influence return ANC visits concerns if the service provided is not perceived as friendly or feeling uncomfortable with the practitioners. The findings of this study suggest the need to tailor health promotion strategies around early uptake of ANC and ensuring return visits.

\section{Abbreviations}

ANC: Antenatal Care; MMR: Maternal Mortality Ratio; FGD: Focus Group Discussion; PHC: Primary Health Care; SSI: Semi-Structured
Interviews; GU: Griffith University; IDR: Indonesia Rupiah; SMS: Short Message Service.

\section{Ethics Approval and Consent to Participate}

Ethics approval was obtained from Griffith University Human Research Ethics Committee (GU ref no: 2019/424) and the Universitas Airlangga (ref no: 15494-KEPK). All participants gave informed written consent.

\section{Competing Interest}

The author declares that there are no significant competing financial, professional, or personal interests that might have affected the performance or presentation of the work described in this manuscript.

\section{Availability of Data and Materials}

The data that support the findings of this study are available from the corresponding author, LJ, upon reasonable request.

\section{Authors' Contribution}

LJ conceptualized and designed the study and research questions, assisted in data collection, data analysis, initial interpretation, and drafted the manuscript. ND carried out data collection and was a supervisor of the project. NW and $\mathrm{NH}$ were supervisors of the project and assisted in overall study design and research questions. ND, NW, and NH reviewed and revised the analyzed data and manuscript. All authors read and approved the final manuscript.

\section{Acknowledgment}

This project was supported by The Ministry of Research, Technology and Higher Education (MRTHE) in Indonesia, Universitas Airlangga, and Griffith University. The authors thank Ratna Wulandari and Ilham Akhsanu Ridlo for their contribution to data collection. The authors also acknowledge Hilda Izzaty, Erin Sebtiarini, Arintika Chorunnisa Islami, Dwi Ratna Paramitha, Arini Novianty, and Tita Rismayanti for their assistance in the data translation. Finally, the authors would like to express their gratitude to all participants in this study.

\section{References}

1. Haftu A, Hagos H, Mehari M, G/her B. Pregnant women adherence level to antenatal care visit and its effect on perinatal outcome among mothers in Tigray public health institutions, 2017: cohort study. BMC Research Notes. 2018; 11 (1).

2. World Health Organization. Trends in maternal mortality: 2000 to 2017. World Health Organization; 2019.

3. Das A. Does antenatal care reduce maternal mortality?. Mediscope. 2017; 4 (1): 1-3.

4. Nababan HY, Hasan M, Marthias T, Dhital R, Rahman A, Anwar I. Trends and inequities in use of maternal health care services in Indonesia, 1986-2012. International Journal of Women's Health. 2018; 10: 11-24.

5. The United Nations Children Fund. Antenatal care - UNICEF DATA. UNICEF DATA; 2019.

6. World Health Organization. 2018 Health SDG profile: Indonesia. Searo.who.int; 2018.

7. Brooks M, Thabrany H, Fox M, Wirtz V, Feeley F, Sabin L. Health facility and skilled birth deliveries among poor women with Jamkesmas 
health insurance in Indonesia: a mixed-methods study. BMC Health Services Research. 2017; 17 (1).

8. Yap W, Pambudi E, Marxoeki P, Jwelwayne S, Tandon A. Maternal health report: revealing the missing link. Documents.worldbank.org; 2017.

9. Agus Y, Horiuchi S. Factors influencing the use of antenatal care in rural West Sumatra, Indonesia. BMC Pregnancy and Childbirth. 2012; 12 (1).

10. Efendi F, Chen C, Kurniati A, Berliana S. Determinants of utilization of antenatal care services among adolescent girls and young women in Indonesia. Women \& Health. 2016; 57 (5): 614-29.

11. Fauk N, Cahaya I, Nerry M, Damayani A, Liana D. Exploring determinants influencing the utilisation of antenatal care in Indonesia: a narrative systematic review. Journal of Healthcare Communications. 2017; 02 (04).

12. Schröders J, Wall S, Kusnanto H, Ng N. Millennium development goal four and child health inequities in Indonesia: a systematic review of the literature. PLOS ONE. 2015; 10 (5): e0123629.

13. Sujana T, Barnes M, Rowe J, Reed R. Decision making towards maternal health services in Central Java, Indonesia. Nurse Media Journal of Nursing. 2017; 6 (2): 68.

14. Rosales A, Sulistyo S, Miko O, Hairani L, Ilyana M, Thomas J, et al. Recognition of and care-seeking for maternal and newborn complications in Jayawijaya district, Papua Province, Indonesia: a qualitative study. Journal of Health, Population and Nutrition. 2017; 36 (S1).

15. Titaley C, Hunter C, Dibley M, Heywood P. Why do some women still prefer traditional birth attendants and home delivery?: a qualitative study on delivery care services in West Java Province, Indonesia. BMC Pregnancy and Childbirth. 2010; 10 (1).

16. Ansariadi A, Manderson L. Antenatal care and women's birthing decisions in an Indonesian setting: does location matter?. Rural Remote Health. 2015; 15 (2): 2959.

17. Titaley C, Hunter C, Heywood P, Dibley M. Why don't some women attend antenatal and postnatal care services?: a qualitative study of community members' perspectives in Garut, Sukabumi and Ciamis districts of West Java Province, Indonesia. BMC Pregnancy and Childbirth. 2010; 10 (1).

18. Hennink MM, Kaiser BN, Weber MB. What influences saturation? Estimating sample sizes in focus group research. Qualitative Health Research. 2019; 29 (10): 1483-96.

19. Palinkas L, Horwitz S, Green C, Wisdom J, Duan N, Hoagwood K. Purposeful sampling for qualitative data collection and analysis in mixed method implementation research. Administration and Policy in Mental Health and Mental Health Services Research. 2013; 42 (5): 533-44.

20. Dilshad R, Latif M. Focus group interview as a tool for qualitative research: an analysis. Pakistan Journal of Social Sciences. 2013; 33 (1): 191-8.

21. DeJonckheere M, Vaughn L. Semistructured interviewing in primary care research: a balance of relationship and rigour. Family Medicine and Community Health. 2019; 7 (2): e000057.

22. Mills A, Durepos G, Wiebe E. Coding: selective coding. Encyclopedia of Case Study Research; 2010.

23. Heitmann K, Svendsen H, Sporsheim I, Holst L. Nausea in pregnancy: attitudes among pregnant women and general practitioners on treatment and pregnancy care. Scandinavian Journal of Primary Health Care. 2016; 34 (1): 13-20.

24. Ebonwu J, Mumbauer A, Uys M, Wainberg M, Medina-Marino A. Determinants of late antenatal care presentation in rural and peri-urban communities in South Africa: a cross-sectional study. PLOS ONE. 2018; 13 (3): e0191903.

25. Ogbo F, Dhami M, Ude E, Senanayake P, Osuagwu U, Awosemo A, et al. Enablers and barriers to the utilization of antenatal care services in India. International Journal of Environmental Research and Public Health. 2019; 16 (17): 3152.

26. Yasuoka J, Nanishi K, Kikuchi K, Suzuki S, Ly P, Thavrin B, et al. Barriers for pregnant women living in rural, agricultural villages to accessing antenatal care in Cambodia: a community-based cross-sectional study combined with a geographic information system. PLOS ONE. 2018; 13 (3): e0194103.

27. Wulandari L, Klinken Whelan A. Beliefs, attitudes and behaviours of pregnant women in Bali. Midwifery. 2011; 27 (6): 867-71.

28. Haddrill R, Jones G, Mitchell C, Anumba D. Understanding delayed access to antenatal care: a qualitative interview study. BMC Pregnancy and Childbirth. 2014; 14 (1).

29. Teklesilasie W, Deressa W. Husbands' involvement in antenatal care and its association with women's utilization of skilled birth attendants in Sidama zone, Ethiopia: a prospective cohort study. BMC Pregnancy and Childbirth. 2018; 18 (1).

30. Ekawati F, Claramita M, Hort K, Furler J, Licqurish S, Gunn J. Patients' experience of using primary care services in the context of Indonesian universal health coverage reforms. Asia Pacific Family Medicine. 2017; 16 (1).

31. Paré G, Trudel M, Forget P. Adoption, use, and impact of e-booking in private medical practices: mixed-methods evaluation of a two-year showcase project in Canada. JMIR Medical Informatics. 2014; 2 (2): e24.

32. Feroz A, Perveen S, Aftab W. Role of mHealth applications for improving antenatal and postnatal care in low and middle income countries: a systematic review. BMC Health Services Research. 2017; 17 (1): 704 .

33. Roberts J, Sealy D, Marshak H, Manda-Taylor L, Gleason P, Mataya $\mathrm{R}$. The patient-provider relationship and antenatal care uptake at two referral hospitals in Malawi: a qualitative study. Malawi Medical Journal. 2015; 27 (4): 145-50.

34. Downe S, Finlayson K, Tunçalp Ö, Gülmezoglu A. Provision and uptake of routine antenatal services: a qualitative evidence synthesis. Cochrane Database of Systematic Reviews; 2019. 